\title{
A review on gastric diverticulum
}

\author{
Farhan Rashid ${ }^{1,2^{*}}$, Ahmed Aber $^{2}$ and Syed Y Iftikhar $^{1}$
}

\begin{abstract}
The gastric fundal diverticulae are rare. They can present with variable symptoms. We are enclosing a literature review on gastric fundal diverticulum. Lessons have emerged which may help in the management of this rare condition in future.
\end{abstract}

\section{Introduction}

Gastric diverticulum (GD) is an outpouching of the gastric wall. GDs are rare and they are commonly detected incidentally during routine diagnostic testing. Prevalence ranges from $0.04 \%$ in contrast study radiographs and $0.01 \%$ - $0.11 \%$ at oesophagogastrodeudenum (OGD) [1,2]. The incidence of gastric diverticulum is equally distributed between males and females and typically may present in the fifth and sixth decades. However it is worth mentioning that it may present in patients as young as 9 years old [3].

The lack of exact pathogonomic symptoms and the vague long history of presenting complaints that can range from dyspepsia to major upper gastrointestinal (GI) bleed make this condition a diagnostic challenge.

We conducted a literature search using the "Pubmed" search engine. The following terms "gastric diverticulum" and "Stomach diverticulum" were used to identify the appropriate papers.

In this review, our emphasis is to highlight on the presentation, the pathophysiology, investigations and different management options for this condition.

\section{Presentation of gastric diverticulum}

Symptoms of GD vary and can imitate those of other common disorders. It is important to note that most GD are asymptomatic but may present with a vague sensation of fullness or discomfort in the upper abdomen. Presenting complaint might also be the result of a major complication of GD. This includes acute upper gastrointestinal bleed or perforation [1,2] (Table 1).

\footnotetext{
* Correspondence: farhan_rashid@hotmail.com

'Department of Upper GI Surgery, Royal Derby Hospital, Graduate Entry

Medical School, Derby, University of Nottingham, UK

Full list of author information is available at the end of the article
}

\section{Patho-physiology}

GD in general is a rare condition; It is found in $0.02 \%$ $(6 / 29900)$ of autopsy studies and in $0.04 \%(165 / 380$ 000) of upper gastrointestional studies [1,3,4]. Meeroff et al reported a prevalence of $0.1-2.6 \%$ in an autopsy series [4].

Seventy-five percent of true gastric diverticula were located in the posterior wall of the fundus of the stomach, $2 \mathrm{~cm}$ below the oesophagastric junction and $3 \mathrm{~cm}$ from the lesser curve. False diverticula were either traction or pulsion and associated with inflammation, other diseases, or both. Diverticula were usually less than $4 \mathrm{~cm}$ in size (range, $3 \mathrm{~cm}$ to $11 \mathrm{~cm}$ ) [5,6].

In the literature review we did identify a proposed hypothesis explaining the pathophysiology of this condition. This hypothesis classifies GD cases into congenital and acquired types, with congenital types being more common [5-8]. Based on a review of embryogenesis it had been suggested how a gastric diverticulum can be located within the retroperitoneal space in an attempt to explain the commonest type to GD.

In the period between the 20th and 50th day of gestation, the stomach is transformed from a fusiform swelling of the foregut into its adult form. At this time, there is a $90^{\circ}$ rotation of the stomach, which carries with it the duodenum, the pancreas, and the dorsal mesentery. The posterior body wall and dorsal mesentery then fuse encapsulating the pancreas within the retroperitoneum and establishing its adult form [9].

A diverticulum of the posterior wall of the gastric fundus hypothetically could herniate through an area of dorsal mesentery before its fusion with the left posterior body wall. Initially, the diverticulum would lie superior to the pancreas. With further extension, the diverticulum could project posterior to the pancreas. 
Table 1 GD presenting symptoms, diagnostic investigations and management

\begin{tabular}{llll}
\hline Symptoms & Investigation & Management & Refs \\
\hline Incidental finding on CT scan & Upper Gl contrast study/CT with oral contrast & None & 18,19 \\
Upper Gl bleed & OGD & OGD \& Adrenaline injection & 22,23 \\
Upper abdominal pain, reflux, bloating & CT with contrast \& OGD & Laparoscopic surgical resection & $1,5,29,30,31$ \\
Upper abdominal pain and anorexia & OGD & PPI & 5,9 \\
Upper abdominal pain & Upper Gl contrast study & Exploratory laparotomy plus diverticulectomy & 5 \\
\hline
\end{tabular}

Acquired gastric diverticula in contrast are pseudodiverticula, less common and typically located in the antrum. They usually present with a background history of other gastrointestinal pathology, such as peptic ulcer disease, malignancy, pancreatitis, or gastric outlet obstruction. Gastric diverticula had been reported following surgical procedures on the stomach, including Roux-en-Y gastric bypass $[4,10,11]$.

\section{Investigations}

Accurate diagnosis is essential given the risk for severe complications, including bleeding and perforation, as well as the association with ectopic mucosa and potential for malignant transformation [12]. The condition can be diagnosed by radiological or endoscopic examinations.

This is usually accomplished with upper gastrointestinal contrast radiographic study (UGI) or oesophagogastrodudenoscopy (OGD). These are the most reliable diagnostic tests but reports in the literature confirm that they can give false negative results [13,14]; especially for a diverticulum with a narrow neck that precludes entry of the contrast or scope. It is stated that the GD is best identified during UGI study using a right, anterior oblique view with the patient in a supine, slightly left lateral decubitus and Trendelenburg position [13-16]. In a large review, Palmer [13] reported that 14 of 262 (5\%) GDs are missed during UGI study. Other reports support the use of OGD $[10,17]$ for diagnosis. Distension of the diverticulum by the scope may mimic the patient's symptoms and this maneuver may indicate which patients would benefit from resection [10]. Other reports suggest that computer tomography scanning may be effective; however, the accuracy of this imaging modality is not widely accepted because of the possible misdiagnosis $[18,19]$.

\section{Management}

There is no specific treatment plan for an asymptomatic diverticulum $[9,20]$. The appropriate management for a symptomatic GD depends mainly on the severity of the presenting complaints.

\section{Medical and non surgical therapy}

Protein pump inhibitors therapy for few weeks is reported to resolve the symptoms in proven cases of GD [9]. However it is important to note that this does not resolve the underlying pathology and some studies report that patients presented again with refractory symptoms of dyspepsia and worsening epigastric pain that did not settle with either protein pump inhibitors or histamine receptor blockers [21].

There are also reports in the literature of successful endoscopic management of cases of gastric diverticulum that presented with active upper GI bleed. None of these studies reported any further complications that warranted further surgical management $[22,23]$.

\section{Surgical management}

Surgical resection is recommended when the diverticulum is large, symptomatic or complicated by bleeding, perforation or malignancy. Both open and laparoscopic resection yield good results. Palmer noted that 6 of 9 patients with symptoms caused by gastric diverticulum who underwent open surgery experienced excellent outcomes [24].

Laparoscopic resection of gastric diverticulum was first described by Fine in 1998 [25]. Since then several cases using the laparoscopic surgical approach have been reported [1,26-32]. All of these cases were successfully managed by laparoscopy, with primary resection of the true gastric diverticulum.

The laparoscopic approach has been described by different authors. The most favourable approach that provides the necessary exposure is by placing the ports in a similar fashion to laparoscopic Nissen fundoplication. This includes a midline port, right upper quadrant, and 2 left upper quadrant ports. The laparoscopic dissection has been performed by either releasing the gastrocolic/gastrosplenic ligament or by mobilizing the short gastric vessels, thus gaining exposure of the superior posterior wall of the stomach. The latter is the most frequently used approach $[24,25,27,28]$. Because all diverticula were true and located in the gastric fundus, the most direct approach was by taking down of the short gastric vessels. Simple resection of the diverticulum with a laparoscopic cutting stapler was reported to be successful [32]

\section{Recent experience of dealing with gastric fundal diverticulum}

A 46 year old male patient, with a 10 year history of GORD, presented with abdominal discomfort and haemoptysis. 


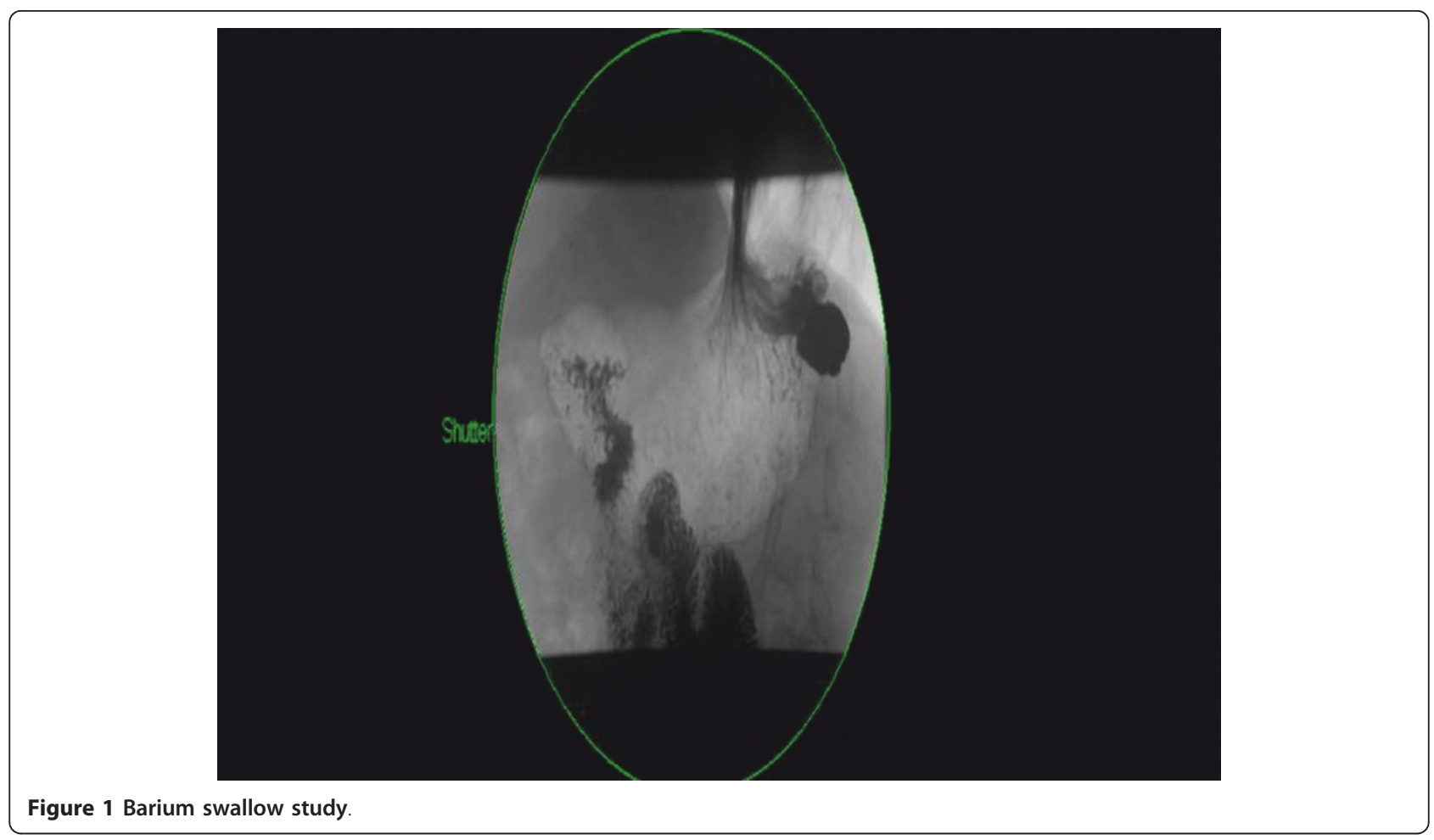

He had also felt nausea and belching with some foul smell. On examination, his abdomen was soft and non tender. He denied any weight loss and was systemically well. All investigations looking for a respiratory cause for his haemoptysis were normal. OGD revealed a gastric fundal pathology, and a small hiatus hernia. The pathology was confirmed with a barium swallow study (Figure 1).

The computed tomography (CT) scan has shown a posterior gastric fundal diverticulum (Figure 2), containing calcified material and measuring approximately 30

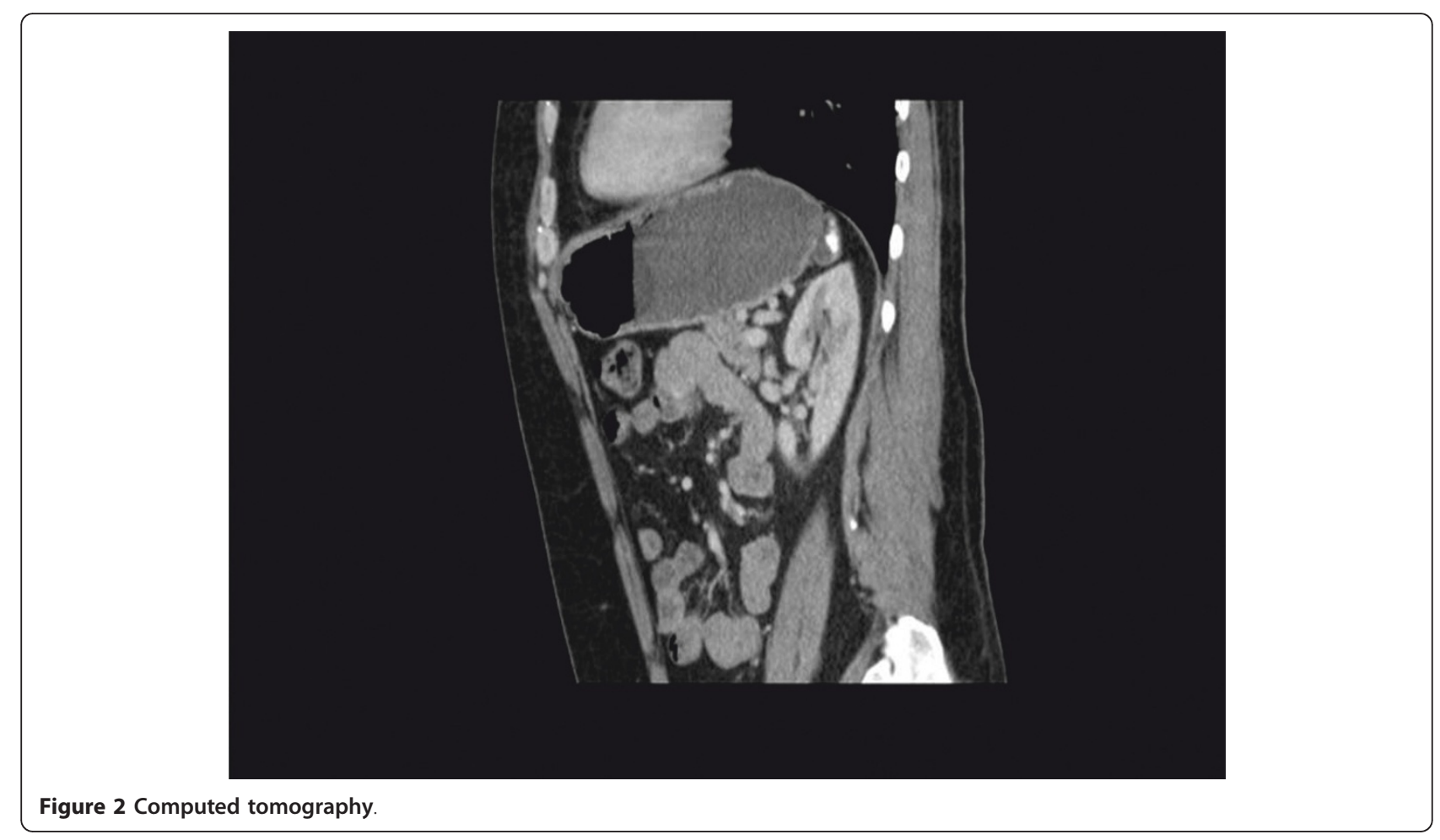


$\mathrm{mm}$ in diameter. The patient underwent laparoscopic excision of gastric fundal diverticulum and had an uneventful recovery from the operation. The histology of the diverticulum confirmed the normal lining of the stomach. The patient remained asymptomatic on further follow up after 1 year.

\section{Conclusion}

A high clinical index of suspicion is needed to diagnose and effectively manage patients with gastric diverticulum. This condition typically present with a long history of vague symptoms such as upper abdominal pain and dyspepsia. It does not always resolve with PPIs and can even be missed on OGD or CT scanning. A focused investigation to look for this particular condition is needed to identify it and subsequently manage it.

We particularly recommend that keep a high index of suspicion in mind especially in patients with a long history of upper abdominal pain and dyspepsia that does not resolve with PPIs and with an insignificant OGD. Although the literature does not describe a standarised approach for the management of this condition, however, we consider laparoscopic repair to be a safe and suitable procedure for this in symptomatic patients who have not responded to medical therapy.

\section{Consent}

Written informed consent was obtained from the patient for publication of this case report and accompanying images. A copy of the written consent is available for review by the Editor-in-Chief of this journal

\section{Author details \\ 'Department of Upper GI Surgery, Royal Derby Hospital, Graduate Entry Medical School, Derby, University of Nottingham, UK. ${ }^{2}$ Department of Surgery, Luton and Dunstable Hospital, Luton, UK.}

\section{Authors' contributions}

FR and AA performed the literature search, extracted the data and wrote the manuscript. SY helped with radiological images and performed the operation. FR, AA and SYI all helped in writing different subsections of the review. All authors contributed to the manuscript, and all read and approved the final version

\section{Competing interests}

The authors declare that they have no competing interests.

Received: 24 October 2011 Accepted: 18 January 2012

Published: 18 January 2012

\section{References}

1. Gockel I, Thomschke D, Lorenz D: Gastrointestinal: Gastric diverticula. J Gastroenterol Hepatol 2004, 19:227.

2. Schiller AH, Roggendorf B, Delker-Wegener S, et al: Laparoscopic resection of gastric diverticula: two case reports. Zentralb/ Chir 2007, 132:251e5.

3. Donkervoort SC, Baak LC, Blaauwgeers JL, et al: Laparoscopic resection of a symptomatic gastric diverticulum: a minimally invasive solution. JSLS 2006, 10:525-7.

4. Meeroff M, Gollan JR, Meeroff JC: Gastric Diverticulum. Am J Gastroeneterol 1967, 47:189-203.
5. Rodeberg DA, Zaheer S, Moir CR, Ishitani MB: Gastric diverticulum: a series of four pediatric patients. J Pediatr Gastroenterol Nutr 2002, 34:564-567.

6. Wolters VM, Nikkels PG, Van Der Zee DC, et al: A gastric diverticulum containing pancreatic tissue and presenting as congenital double pylorus: case report and review of the literature. J Pediatr Gastroenterol Nutr 2001, 33:89-91.

7. Cotea E, Vasilescu A, Dimofte G, et al: Gastric diverticula on the greater curvature. J Chir lasi 2007, 3:269-273.

8. Love L, Meyers MA, Churchill RJ, Reynes CJ, Monceda R, Gibson D: Computed tomography of extraperitoneal spaces. AJR 1981, 136:781-789.

9. Mohan P, Ananthavadivelu, Venkataraman J: Gastric Diverticulum. CMAJ 2010, 182(5):226

10. Anaise D, Brand DL, Smith NL, Soroff HS: Pitfalls in the diagnosis and treatment of a symptomatic gastric diverticulum. Gastrointestinal Endoscopy 1984, 30:28-30.

11. Schweiger F, Noonan J: An unusual case of gastric diverticulosis. Am J Gastroenterol 1991, 86:1817-9.

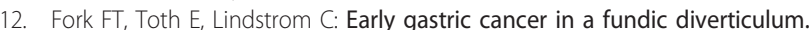
Endoscopy 1998, 30(1):S2

13. Palmer ED: Collective review: gastric diverticula. Int Abstr Surg 1951 92:417-428.

14. Seltzer M, Koch A: A huge gastric diverticulum. Dig Dis 1971, 16:167-170.

15. Bothen N, Eklof O: Diverticula and duplications (enterogenous cysts) of the stomach and duodenum. Am J Roentgenol, Radium Ther Nucl Med 1966, 96:375-381.

16. Eras $P$, Bernbaum S: Gastric diverticula: congenital and acquired. Am J Gastroenterol 1972, 57:120-132

17. Velanovich V: Gastric diverticulum. Surg Endosc 1994, 8:1338-9.

18. Kodera R, Otsuka F, Inagaki $K$, et al: Gastric diverticulum simulating left adrenal incidentaloma in a hypertensive patient. Endocrine Journal 2007, 54(6):969-974.

19. Araki A, Shinohara M, Yamakawa J, et al: Gastric diverticulum preoperatively diagnosed as one of two left adrenal adenomas. Int J Urol 2006, 13:64-66

20. Harford W, Jeyarajah R: Diverticula of the pharynx, esophagus, stomach, and small intestine. In Sleisenger \& Fordtran's gastrointestinal and liver disease.. 8 edition. Edited by: Feldman M, Friedman L, Brandt L, et al. Philadelphia (PA): Saunders; 2006:465-77.

21. MaCauley M, Bollard E: Gastric Diverticulum: A rare cause of refractory epigastric pain. The American Journal of Medicine 2010, 123:5-6.

22. Zakary N, Langenberg DR, Alshumrany M, Schoeman M: Acute haemorrhage from dieulafoy lesion within a gastric diverticulum managed endoscopically. J Gastroenterol Hepatol 2009, 24:1891.

23. Chen J, Su W, Chang C, Lin H: Bleeding from gastric diverticulum. J Gastroenterol Hepatol 2008, 23:336.

24. Palmer ED: Gastric Diverticulosis. Am Fam Phys 1973, 7(3):114-117.

25. Fine A: Laparoscopic resection of a large proximal gastric diverticulum. Gastrointest Endosc 1998, 48(1):93-95.

26. Kim SH, Lee SW, Choe WJ, Choe SC, Kim SJ, Koo BH: Laparoscopic resection of gastric diverticulum. J LaparoendosC Adv Surg Tech 1999, 9(1):87-91.

27. Vogt DM, Curet MJ, Zucker KA: Laparoscopic management of gastric diverticula. J Laparoendosc Adv Surg Tech A 1999, 9(5):405-410.

28. Alberts MS, Fenoglio M: Laparoscopic management of a gastric diverticulum. Surg Endosc 2001, 15(10):1227-1228.

29. MaCauley M, Bollard E: Gastric Diverticulum: A rare cause of refractory epigastric pain. The American Journal of Medicine 2010, 123:5-6.

30. Hewa TL, Zhang Z, Rozelle C, Terry A: Gastric antral diverticulum with heterotopic pancreas in a teenage patient. JPGN 2011, 53(5):471.

31. McKay R: Laproscopic resection of a gastric diverticulum: a case report. JSLS 2005, 9:225-228

32. Rashid F, Singh R, Cole A, Iftikhar SY: Troublesome belching with fetor odour. Gut 2010, 59(3):310-324.

doi:10.1186/1749-7922-7-1

Cite this article as: Rashid et al:: A review on gastric diverticulum. World Journal of Emergency Surgery 2012 7:1. 